\title{
NATUREZA E SOCIEDADE: UMA RECUPERAÇÃO DA TRAJETÓRIA DO MARXISMO ECOLÓGICO E SEU IMPACTO NAS PESQUISAS DAS CIÊNCIAS AMBIENTAIS NO BRASIL
}

\author{
Ivan Penteado Dourado ${ }^{1}$ \\ Gabriela Dias Blanco²
}

\begin{abstract}
RESUMO
A criação de novas linhas e áreas de pesquisas, suas articulações e tentativas de superação das fronteiras estanques das disciplinas, constituem elementos ricos para entender a própria constituição do pensamento científico. No momento em que a Sociologia passa a se ocupar também pelos problemas ambientais, diferentes perspectivas emergem no campo das pesquisas sobre 0 ambiente, entre elas a do Marxismo Ecológico/Ambiental. A presente pesquisa objetiva resgatar a riqueza da perspectiva conhecida como Marxismo Ecológico, mapeando o impacto desta nas pesquisas oriundas de programas de pós-graduação do campo das Ciências Ambientais no Brasil. Esse mapeamento encontrouum grupo muito restrito de pesquisas que dialogam com essa perspectiva, indicando a necessidade de uma agenda de pesquisa futura e o estímulo para a inserção de suas problematizações nos debates sobre a questão ambiental.
\end{abstract}

Palavras-chave: Marxismo Ecológico; Ecossocialismo; Sociologia Ambiental; Ciências Ambientais.

\begin{abstract}
The creation of new lines and research areas, as well as the articulations and attempts to overcome the watertight frontiers of the disciplines are rich elements to understand the constitution of scientific thinking.At a time when sociology is also concerned with environmental problems, different perspectives emerge in the field of environmental research, including Ecological/Environmental Marxism. The present research aims to recover the richness of the perspective known as Ecological Marxism, mapping the impact of this in the postgraduate orientation research of the field of Environmental Sciences in Brazil. This mapping found a very narrow group of researches that dialogue with this perspective, indicating the need for a future research agenda and the stimulus for insertion of its problematizations in the debates on the environmental issue.
\end{abstract}

Keywords: Ecological Marxism; Ecosocialism; Environmental Sociology; Environmental Sciences.

\footnotetext{
${ }^{1}$ Universidade de Passo Fundo - UPF. Programa de Pós-Graduação em Educação.

${ }^{2}$ Doutoranda do Programa de Pós-Graduação em Sociologia UFRGS.
} 


\section{INTRODUÇÃO}

A discussão sobre a realidade pelo caminho científico revela mais sobre a forma com que a ciência se fundamenta do que sobre a própria realidade. Esse princípio inspirado nas discussões de Pierre Bourdieu et al (1991) sobre a ciência ou, dentro de sua definição, o campo cientifico, apresenta uma dimensão de entendimento extremamente rica. A partir dela, é possível destacar a necessidade de uma "problemática teórica que permita submeter a uma interrogação sistemática os aspectos da realidade colocados em relação entre si pela questão que lhes é formulada". (BOURDIEU; CHAMBOREDON; PASSERON, 1991, p. 48). Ao invés de falarmos de ciência, dentro de um entendimento monolítico, falamos de campo científico, onde existem disputas e pensamentos que, em determinados momentos históricos, são dominantes e, em outros, acabam perdendo seu lugar de destaque. Da mesma forma, é possível falar de tradições e escolas de pensamento, que criam possibilidades analíticas muito diversas dentro do próprio pensamento científico.

Se em um primeiro momento, após a emergência das áreas do conhecimento científico, a natureza foi identificada como um objeto de análise, foram as chamadas "Ciências da Natureza" as que se estabeleceram como detentoras absolutas desta produção científica. As Ciências Sociais e, mais precisamente, a Sociologia, passaram a ocupar suas produções com esse objeto muito tardiamente e, em grande medida, impulsionadas pela emergência dos chamados "problemas ambientais", na década de 1970. Neste processo, olhares que até então não problematizavam a dimensão "natural" da sociedade ou a dimensão "social' da natureza (enquanto uma construção social e cultural), passaram a se consolidar como possibilidades também legítimas de análise, podendo-se falar no surgimento de uma sociologia do ambiente ${ }^{3}$.

Os caminhos adotados, contudo, divergiram ao longo do tempo assumindo múltiplas perspectivas epistemológicas e ontológicas. Alguns autores do campo da Sociologia defenderam a necessidade de novos marcos

\footnotetext{
${ }^{3}$ Aqui, parte-se da compreensão de ambiente como sendo "o conjunto de meios naturais ou artificializados da ecosfera onde os seres humanos se instalaram, que exploram e administram, e o conjunto dos meios não antropizados necessários à sua sobrevivência" (FLEURY; ALMEIDA; PREMEBIDA, 2014, p.35).
} 
teóricos, ou mesmo a adoção de perspectivas teórico-metodológicas de outros campos do conhecimento, a fim de tornar possível a análise das múltiplas dimensões da questão ambiental. Em última instância, tratava-se de assumir a impossibilidade de uma análise da questão ambiental por meio dos referenciais e arcabouços teóricos já estabelecidos na Sociologia. Outros, contudo, encontraram em teorias sociológicas já consolidadas a dimensão de um "pensamento ecológico" até então negligenciado. E, neste sentido, procuraram trazer as contribuições de "clássicos" para a análise atual de problemas ambientais.

Neste artigo, serão enfocadas as principais contribuições da teoria de Karl Marx para uma análise atual da questão ambiental. Pode-se dizer, conforme Foster (2012), que está presente em Marx, já em seus primeiros escritos $^{4}$, uma forte crítica ecológica que identifica o capitalismo como um sistema de usurpação da natureza e da riqueza. Esta concepção é identificada nas análises empreendidas pelo autor acerca, por exemplo, do processo de acumulação primitiva (no qual camponeses passaram a ser removidos de suas terras como parte do desenvolvimento capitalista); das distinções entre valor de uso e valor de troca (sendo o primeiro associado aos requisitos da produção em geral e às relações do ser humano com a natureza, e o segundo associado à busca pelo lucro) e da chamada fenda metabólica (que colocou em evidência o progressivo deterioramento da terra, a partir do transporte em distâncias cada vez maiores de alimentos e fibras até os grandes centros urbanos).

Sendo assim, o presente artigo objetiva percorrer a emergência do Marxismo Ecológico, especialmente no campo de estudos da Sociologia, e as possibilidades ainda pouco exploradas nas pesquisas oriundas das Ciências Ambientais. A questão norteadora do presente artigo será: quais as contribuições ainda não exploradas pelos Programas de Pós-Graduação em Ciências Ambientais nas discussões do Marxismo Ambiental? Passamos agora à apresentação da nossa discussão teórica e, na sequência, indicar os aspectos encontrados nas pesquisas analisadas.

\footnotetext{
${ }^{4}$ Ver, de Karl Marx, as obras "Debates acerca da lei do furto da madeira" (1842) e "Manuscritos econômico-filosóficos" (1844).
} 


\section{APORTES TEÓRICOS: MARXISMO ECOLÓGICO E A TRADIÇÃO SOCIOLÓGICA}

As Ciências Sociais se originaram na Idade Moderna relacionadas ao paradigma das Ciências da Natureza. A concepção de uma ciência positiva e a motivação em igualar suas metodologias as já legitimadas metodologias das Ciências Naturais, fizeram com que se estabelecesse uma ruptura identificada como dicotomia ao longo do desenvolvimento do campo científico entre natureza e sociedade, ou ainda, natureza e cultura. A Sociologia, em particular, fundou-se na máxima presente em Émile Durkheim de que "um fato social só pode ser explicado por outro fato social". Esta é a sua base epistemológica e teórica. Profundamente influenciada pela cultura ocidental tradicional, a Sociologia, assim como as demais Ciências Sociais, é marcada por um forte antropocentrismo que vê o ser humano como separado do resto dos seres vivos, com poderes para dominar a natureza e usá-la para os seus próprios fins. Este otimismo nas capacidades excepcionais do ser humano deveu-se, sobretudo, ao contexto de expansão econômica e tecnológica que caracterizou a visão ocidental dominante.

A partir da década de 1970, com a difusão do debate sobre os problemas ambientais globais levado a cabo pelo movimento ambientalista ${ }^{5}$, coloca-se em xeque a capacidade de domínio do ser humano sobre a natureza, e questionam-se os pressupostos modernos presentes na ciência e na sua premissa epistemológica de separação entre sociedade e natureza. Estes questionamentos, contudo, não se deram de modo unívoco. Como destacam Escalera-Briceño, Ángeles-Villa e Palafox-Muñoz (2018), dentro do movimento ambientalista e, especialmente, nas aproximações que passaram a ser feitas entre economia e ecologia, é possível identificar, neste período, a presença de duas grandes perspectivas: uma, atrelada a uma tradição positivista, que defendia a necessidade de continuar sustentando uma racionalidade

\footnotetext{
${ }^{5}$ Comumente, identifica-se a década de 1970 como o período de surgimento do ambientalismo enquanto um movimento "global" (especialmente, pela criação do "Dia da Terra" em abril de 1970). Contudo, cabe ressaltar que as raízes do pensamento ambientalista remontam de muito antes. Para um maior aprofundamento, ler: MCCORMICK, John. Rumo ao Paraíso: A história do movimento ambientalista. Rio de Janeiro: Relume Dumará, 1992.
} 
econômica para a solução da crise ambiental - com foco no debate sobre a escassez e soluções construídas pelo mercado e; outra, focada na necessidade de construção de uma sustentabilidade que não tivesse relação com o poder tecnocrático, mas com a coprodução do conhecimento.

Conforme Fleury, Almeida e Premebida (2014, p.35-36), é neste período que nas Ciências Sociais e, mais particularmente na Sociologia, surge um campo de estudos "vinculado a um processo de demanda por análises teóricas capazes de articular o social e o natural, podendo-se identificar na constituição daquela que se convencionou chamar de sociologia ambiental um de seus primeiros acolhimentos". Este campo estava, em grande medida, influenciado pelos debates e controvérsias presentes no movimento ambientalista e passou a se constituir, como era de se esperar, também por perspectivas múltiplas e divergentes.

Referindo-se especificamente à denominada Sociologia Ambiental, os autores destacam que esta se constituiu, basicamente, a partir de três grandes perspectivas: a realista, a construcionista e a do marxismo ambiental/ecológico ${ }^{6}$. Enquanto a perspectiva realista enfatiza a existência real e objetiva dos problemas ambientais, direcionando-se à análise da verdade sobre estes problemas (acessada por meio do conhecimento científico), a perspectiva construcionista parte da premissa de que os problemas ambientais são construções sociais, nas quais envolvem-se diferentes grupos e atores sociais e que, portanto, cabe à Sociologia Ambiental a análise sobre as percepções e representações existentes sobre estes problemas. Pode-se dizer que a perspectiva realista é, em si, materialista. Contudo, a explicação por ela formulada para a existência de uma crise ambiental difere, substancialmente,

\footnotetext{
${ }^{6}$ Vale salientar que, para além da abordagem denominada de sociologia ambiental, os autores identificam ainda a existência de mais quatro grandes abordagens, dentro do campo de estudos sociológicos sobre a questão ambiental. São elas: a) abordagem de uma sociologia geral, que passa a analisar os problemas ambientais como características da modernidade (com as contribuições da modernização ecológica e sociedade de risco); b) abordagem da sociologia rural, com seu debate sobre novas ruralidades e a compreensão do meio rural como espaço ambiental; c) os Estudos sobre Ciência e Tecnologia, que centram a análise na própria produção do conhecimento científico e, particularmente no contexto latino-americano; d) a abordagem dos conflitos ambientais, na qual a correlação entre ambiente e conflitos adquire posição central - seja associada ao discurso da biodiversidade ou como componente inerente à cosmopolítica (FLEURY; ALMEIDA; PREMEBIDA, 2014).
} 
da elaborada pela perspectiva do marxismo ecológico - terceira corrente influente na Sociologia Ambiental e foco deste artigo.

Enquanto para os realistas as instituições culturais são as responsáveis pela crise ambiental, os marxistas ecológicos defendem que as relações capitalistas de produção e a natureza das instituições estatais modernas são os seus verdadeiros responsáveis (OLIVIERI, 2009). Desta forma, o marxismo ecológico centra-se no objetivo de aprofundar a teoria marxista, no sentido de identificar as formas pelas quais o capital se limita, afetando suas próprias condições sociais e ambientais, elevando seus custos e gastos e, neste sentido, impulsionando o surgimento de crises econômicas. Dentro da Sociologia Ambiental, seus autores expoentes foram os sociólogos norteamericanos Allan Schnaiberg e James O'Connor.

Schnaiberg desenvolveu - junto a colaboradores - dois conceitos que se tornaram importantes para as futuras análises do marxismo ambiental: o conceito de "esteira de produção"7 (traduzido em alguns textos como "rotina de produção") e o de "dialética sociedade-ambiente". Tratando-se do conceito de "esteira de produção", pode-se dizer, seguindo Schnaiberg, Weinberg e Pellow (1998), que ele expressa uma economia política impulsionada por vários fatores centrais.

Primeiramente, há a suposição social e política da necessidade de expansão contínua da produção industrial e do crescimento econômico, sendo a expansão econômica considerada como o núcleo de qualquer programa social, econômico ou ambientalmente viável. Nesta perspectiva, considera-se que o aumento da produção e dos lucros dos capitalistas beneficiam os trabalhadores com o aumento de oportunidades de trabalho e salários. Em segundo lugar, a "esteira de produção" é estruturada pela necessidade de garantir que o aumento do consumo acompanhe a produção. Assim, o Estado passa a trabalhar junto ao capital privado para disponibilizar empréstimos aos consumidores. Em terceiro lugar, conforma-se a crença sociopolítica de que os problemas sociais e ecológicos são melhor resolvidos por meio do aumento do

\footnotetext{
${ }^{7}$ Há diferentes definições para "esteira de produção", sendo referenciada por alguns autores como uma teoria, para além de um conceito. Para um maior aprofundamento sobre estas diferenças, ler: BUTTEL, Frederick. The treadmill of production: An Appreciation, Assessment, and Agenda of research. In: Organization \& Environment. Vol 17, nº 3, pp. 323 - 336, 2004.
} 
ritmo da "esteira", ou seja, a solução é melhor alcançada através do mercado. Em quarto lugar, vincula-se fortemente o crescimento econômico com a expansão do desenvolvimento corporativo, no sentido de que as grandes empresas são tidas como o motor da economia (o que favorece o estabelecimento de monopólios). E, por último, há um constante reforço de todos os fatores anteriores através de iniciativas de socialização econômica e política por parte de empresas centrais e suas instituições dependentes (como associações comerciais, de publicidade, programas educacionais, entre outros).

Por trás do conceito acima referenciado, está a ideia de uma "dialética sociedade-ambiente", desenvolvida também por Schnaiberg em seus trabalhos. De acordo com Buttel (1992) a dialética sociedade-ambiente funda-se na tese de que "o crescimento econômico é uma aspiração social" e na antítese de que "a ruptura ecológica é uma consequência inevitável da expansão econômica". Assim, de modo muito semelhante ao que Karl Polanyi já havia feito na sua obra "A grande transformação" de 1944, Schnaiberg (1975) enfatizou que o crescimento do mercado e das relações econômicas capitalistas leva, invariavelmente, a uma maior exploração e destruição ambiental e que estas, por consequência, acabam por trazer restrições à expansão econômica futura e às condições sociais e ambientais de existência.

Ainda segundo o autor, a solução da dialética estaria em três sínteses: a econômica, a de escassez planejada e a ecológica. A diferença entre elas residiria na ênfase dada ao crescimento econômico e ao papel do Estado no controle ambiental. Enquanto na síntese econômica haveria uma maximização do crescimento econômico, sem preocupação com os problemas ambientais, na síntese da escassez planejada haveria um controle apenas dos problemas ambientais considerados mais graves e se esperaria um crescimento moderado. Já na síntese ecológica (de caráter hipotético), haveria o empreendimento de grandes esforços para o fim da destruição ambiental, em paralelo a uma restrição da expansão econômica. Assim, relacionando a "dialética sociedade-ambiente", presente no modo de produção capitalista, ao conceito de "esteira de produção", tem-se que "o fato de que o crescimento intensivo em capital crie os deslocamentos e demandas políticas que fazem 
aumentar novamente o gasto estatal em crescimento intensivo em capital, fomentando-o ad infinitum, constitui-se [como] a essência do caráter "treadmill" [esteira] do capitalismo industrial moderno, além de produzir sua crise fiscal endêmica. (OLIVIERI, 2009, p.46).

As formulações iniciais de Allan Schnaiberg dialogam, em grande medida, com as contribuições de James O'Connor (2001). Segundo o autor, o ponto de partida da teoria marxista tradicional sobre a crise econômica e a transição ao socialismo é a contradição entre as forças produtivas e as relações de produção capitalistas. Em contraste, para a teoria marxista ecológica, o ponto de partida é a contradição entre "as relações de produção capitalistas (e as forças produtivas), por um lado, e as condições de produção capitalista, ou 'relações e forças de reprodução social capitalistas' por outro" (O'CONNOR, 2001, p.195, tradução nossa). Para Marx, há três tipos de condições de produção: as condições físicas externas, a força de trabalho e as condições comunais/gerais da produção social. $\mathrm{Na}$ atualidade, esclarece O’Connor (2001),

(...) as "condições físicas externas" são analisadas em termos da viabilidade dos ecossistemas, os níveis adequados de ozônio atmosférico, a estabilidade das linhas costeiras e bacias hidrográficas, a qualidade do solo, o ar e a água e coisas pelo estilo. A "força de trabalho" se discute em termos de bem-estar físico e mental dos trabalhadores, a classe e o grau de socialização dos mesmos e dos seres humanos, em geral, como forças produtivas sociais e organismos biológicos. As "condições comunais" se analisam em termos de "capital social", a "infraestrutura", e assim sucessivamente (incluindo, muito recentemente, o "capital comunitário"). (O'CONNOR, 2001, p.195, tradução nossa).

Neste sentido, o autor destaca que tanto a força de trabalho humana, como a natureza externa e as infraestruturas, incluindo suas dimensões espaciais e temporais, não se produzem de maneira capitalista, ainda que o capital trate estas condições de produção como se fossem mercadorias. Por isto, suas condições de oferta (quantidade e qualidade, lugar e tempo) precisam ser reguladas pelo Estado ou pelos capitais que atuam como se fossem o Estado. O que faz com que sua disponibilidade dependa

(...) do poder político do capital, do poder dos movimentos sociais que questionam determinadas formas capitalistas de condições de produção (por exemplo, as lutas pela terra como meio de produção e não como meio de consumo), das estruturas estatais que mediam ou 
ocultam os conflitos acerca da definição e o uso das condições de produção (por exemplo, conselhos de zoneamento) e outros. (O'CONNOR, 2001, p.201, tradução nossa).

Evidencia-se, portanto, uma segunda contradição do capitalismo. Enquanto a primeira, identificada por Marx, diz respeito à exploração do trabalho (mais-valia) levando à luta de classes (contradição interna ao capitalismo), a segunda, destacada por O'Connor (2001), refere-se às condições de produção capitalista, uma vez que a destruição ou escassez das mesmas leva, necessariamente, a formas mais sociais de provisão por meio da política e da ideologia. Desta forma, O'Connor (2001, p.191, tradução nossa) afirma que, "o marxismo tradicional esclarece as práticas dos movimentos tradicionais de trabalhadores e, de maneira similar, o marxismo ecológico pode esclarecer as práticas dos novos movimentos sociais".

Perspectiva semelhante é adotada por John Bellamy Foster, sociólogo também norte-americano, que desenvolveu nas últimas décadas uma série de estudos que trazem à luz o que ele chama de uma "crítica ecológica de Marx". Marx considerava haver uma necessária "interação metabólica" entre os seres humanos e a natureza, sendo o trabalho um processo de mediação central:

\begin{abstract}
Antes, o trabalho é um processo entre o homem e a natureza, um processo em que o homem, por sua própria ação, medeia, regula e controla seu metabolismo com a Natureza. Ele mesmo se defronta com a matéria natural como uma força natural. Ele põe em movimento as forças naturais pertencentes à sua corporeidade, braços, pernas, cabeça, mãos, a fim de se apropriar da matéria natural numa forma útil à própria vida. Ao atuar, por meio desse movimento, sobre a natureza externa a ele e ao modificá-la, ele modifica, ao mesmo tempo, a sua própria natureza. (MARX, 1983, p.149).
\end{abstract}

Assim, os sistemas naturais têm seu metabolismo próprio, que opera independentemente e em relação à sociedade humana, permitindo sua regeneração e/ou continuação. Conforme Foster (2012), cada modo de produção gera uma ordem metabólica social particular, que influencia as relações sociedade-natureza. O que Marx analisou, partindo dos trabalhos do químico alemão Justus Von Liebig, foi que o transporte de alimentos e fibras, realizado por centenas de quilômetros até os novos centros urbanos industriais levava, invariavelmente, a uma perda significativa dos nutrientes do solo e, ao 
mesmo tempo, a um aumento expressivo da poluição das cidades (o que Liebig chamava de "Raubbau" ou o "sistema de roubo"). Deste modo, estabelecia-se uma "fenda metabólica" na relação sociedade-natureza, uma vez que o capitalismo gerava uma forma de agricultura mecanizada, que dividia industrialmente a natureza, do mesmo modo como o fazia com o trabalho.

Neste sentido, John Foster (2012), partindo do conceito de "fenda metabólica" de Marx, realizou uma brilhante análise das relações, historicamente estabelecidas, não apenas no interior das economias capitalistas avançadas, mas também entre os países ditos "centrais" e "periféricos". Para a análise destas relações, utilizou-se do termo "imperialismo ecológico". Segundo o autor, a manutenção e expansão do sistema-mundo do capital depende da constante expoliação de recursos do hemisfério Sul para o hemisfério Norte. Como exemplo, em um estudo desenvolvido em parceria com o sociólogo Brett Clark, o autor analisou a brutal experiência de exploração do guano $^{8}$ no Peru e Chile do século XIX, que serviu como importante fonte de fertilização do solo de regiões como a Grã-Bretanha. Nas palavras dos autores:

Particularmente, o comércio internacional de guano no século XIX põe em relevo a emergência de uma fratura metabólica global, dado que o guano e os nitratos eram transferidos desde o Peru e Chile até a Grã Bretanha (e outras nações) com o propósito de enriquecer seus solos exaustos. Esta fenda metabólica global supôs o declínio da fertilidade do solo na Grã-Bretanha, a transferência de trabalhadores chineses ao Peru para trabalhar nas ilhas de guano, a exportação de fertilizante natural às nações centrais, a degradação do ambiente peruano/chileno, a criação de economias endividadas e a Guerra do Pacífico, já que o Chile (apoiado secretamente pela Grã-Bretanha) e o Peru lutaram entre si para controlar os recursos desejados pelos britânicos. (CLARK; FOSTER, 2012, p.3, tradução nossa).

Como conclusão, o autor sustenta que a "fenda metabólica" identificada por Marx na relação sociedade-natureza, já no século XIX, evoluiu, atualmente, para múltiplas "fendas ecológicas", transgredindo as fronteiras entre humanidade e planeta. Neste sentido, avançando a partir de Marx, Foster (2012, p.101) afirma que "não é somente a escala de produção, mas, bem

\footnotetext{
${ }^{8} \mathrm{O}$ guano se refere à matéria resultante do acúmulo de excrementos de aves marinhas, que se apresenta como um ótimo fertilizante para o solo. No Peru do século XIX, as Ilhas Chincha eram o principal "depósito" de guano do mundo.
} 
ISSN- 1413-8638

E-ISSN - 2238-5533

v. 23, n. 3, p. 85-104, 2018

mais, a estrutura de produção que tem a culpa da versão contemporânea do Raubbau capitalista".

\section{CIÊNCIAS AMBIENTAIS E O MARXISMO ECOLÓGICO NO BRASIL}

Apesar da riqueza das contribuições teóricas apresentadas anteriormente para a análise da questão ambiental - seja a partir de uma retomada direta do "pensamento ecológico" de Karl Marx, ou de uma releitura da teoria marxista com a proposição de avanços e novas formulações - podese dizer que o chamado Marxismo Ecológico alcançou, até o momento, uma influência tímida dentro do campo de estudos da Sociologia Ambiental e, mais ainda, entre os estudos da grande área das Ciências Ambientais. No Brasil, perspectivas teóricas como a da Modernização Reflexiva/Sociedade de Risco e da Modernização Ecológica ${ }^{9}$ parecem ter conquistado maior interesse e destaque entre os pesquisadores, apresentando desdobramentos em discussões referentes à gestão e/ou governança ambiental. Frutíferos debates podem ser evidenciados a partir destas produções, porém, uma crítica ao capitalismo em sua dimensão mais estrutural parece manter-se ausente. Concomitantemente - e de modo relacionado - observa-se um fortalecimento, tanto nas produções acadêmicas como no ambientalismo de modo geral, das ditas "soluções de mercado" e/ou a defesa de um simples aprimoramento dos mecanismos de controle da própria ciência e tecnologia para o enfrentamento dos problemas ambientais.

Procurando evidenciar a persistente ausência - ou baixa apropriação da perspectiva teórico-crítica do Marxismo Ecológico, apresentaremos a seguir o resultado do mapeamento das poucas referências encontradas alinhadas a esta perspectiva nas produções da área de Ciências Ambientais no Brasil. O objetivo com este mapeamento é incentivar o aprofundamento deste campo de estudos, considerando-se suas potencialidades para a construção de análises de caráter mais estrutural em relação à chamada crise ambiental, conscientes, claro está, de suas também limitações. Para a realização das buscas,

\footnotetext{
${ }^{9}$ Para saber mais sobre a primeira perspectiva, ler: BECK, Ulrich; GIDDENS, Anthony; LASH, Scott. Modernização reflexiva. Unesp, 1995. Já com respeito à Modernização Ecológica, sugerimos: MOL, Arthur PJ; SPAARGAREN, Gert. Ecological modernisation theory in debate: a review. Environmental politics, v. 9, n. 1, p. 17-49, 2000.
} 
utilizamos os termos "marxismo" e "ecológico" em um primeiro momento e, depois, "ecossocialismo", visto que estes muitas vezes são empregados de modo indiferenciado.

Em uma busca ao Catálogo de Teses e Dissertações da Capes com os termos "marxismo" e "ecológico" foram encontrados 81 resultados nas áreas do conhecimento relacionadas às "Ciência Ambientais" e a "Ecologia". Destes, após o mapeamento mais detalhado com o critério de produções posteriores à criação da Plataforma Sucupira e que estavam disponíveis para download, encontramos 37 estudos para análise. Procedemos à leitura das pesquisas, ou seja, realizamos a leitura para além dos títulos e resumos, por acreditar que essas discussões podem estar expressas de diferentes formas ao longo da produção científica, mesmo que não ocupem lugar central nas discussões. Após um mapeamento mais detalhado, onde os termos Marx e/ou Marxismo foram referenciados no corpo dos textos das pesquisas, descartando as que apenas referenciavam no título das obras constantes nas referências ou mesmo para justificar apenas um parágrafo de forma muito indireta ${ }^{10}$, observamos que apenas 4 pesquisas recuperam discussões dessa natureza e magnitude. A seguir, apresentamos uma síntese destas pesquisas.

A pesquisa de mestrado de Alexander Salah Bakri, intitulada Valor e Sustentabilidade: Um estudo comparativo entre Economia Ambiental Neoclássica, Economia Ecológica e Marxismo Ecológico (2018) constitui o trabalho mais recente e mais rico no que diz respeito ao potencial da recuperação do Marxismo Ecológico nas pesquisas ambientais. O estudo objetiva uma sistematização dos esquemas analíticos por meio de três escolas de pensamento, a Economia Ecológica, a Economia Ambiental Neoclássica e o Marxismo Ecológico. Ao longo da sua pesquisa, é apresentado como cada uma destas tradições auxilia na resposta à atual crise ecológica dentro de um sistema global de produção e consumo. Em especial, ao recuperar a tradição

\footnotetext{
${ }^{10}$ Podemos citar como exemplo a tese de Fabian Viégas, "Proposta de índice de conservação hídrica para o ICMS Ecológico do Estado do Rio Grande do Sul" (2017), com sua discussão sobre o ICMS Ecológico e, mais especificamente, a questão hídrica e sua relação com os repasses de recursos e suas ações de preservação. Nesta pesquisa, a citação à Marx ocorre apenas em um momento específico, quando ele traz a problematização sobre as contradições inerentes à ideia de uma "universalização dos direitos humanos", desde a Revolução Francesa. A pesquisa ilustra ensaios de aproximação teórica, pelo caminho de uma discussão indireta e não central, em pesquisas no campo das Ciências Ambientais.
} 
do Marxismo Ecológico, o autor faz referência a teóricos já apresentados neste artigo, como Allan Schaiberg, James O'Connor e John Bellamy Foster, além de outros como André Gorz (1994), Karl Polanyi (2000), Joan Martínez-Alier (2015) e Michael Löwy (2005) ${ }^{11}$.

O estudo de Maria da Conceição Reis Maia, intitulado Contribuições do Curso Superior de Tecnologia em Gestão Ambiental do IFPE para a Formação do Sujeito Ecológico (2015) constitui um trabalho ilustrativo do uso de Marx, porém, em uma parte muito específica de sua pesquisa, já que ela não referencia o Marxismo Ecológico, mas apenas um recorte de Marx, pelos teóricos da educação. $O$ foco é reconstituir a formação do sujeito ecológico, referenciando pensadores como Paulo Freire (2004), Enrique Leff (2006) e Leonardo Boff (1999) ${ }^{12}$.

$\mathrm{Na}$ mesma linha da pesquisa anterior, Verônica Maria Rodrigues da Silva, com seu trabalho intitulado A Formação do Sujeito Ecológico no Instituto Capibaribe (2016), analisa como se constitui a formação desse sujeito ecológico na escola, utiliza um conjunto de referências das quais apenas duas são oriundas da tradição da Sociologia Crítica, com Mikhail Bakhtin (1999) e Vygotsky $(1984,1993)^{13}$. Como essa discussão se alinha de forma muito semelhante à pesquisa anterior e não avança na discussão do Marxismo Ecológico, ficaremos apenas na constatação deste tipo de recuperação mais pontual e representativa nas pesquisas do campo da educação ambiental, por um viés mais crítico.

Por fim, a pesquisa de mestrado de Gabriel Trettel Silva, intitulada $O$ decrescimento: leituras a partir do Sul global (2017), discute a redução econômica dos países (o decrescimento) e o impacto que este processo possui

\footnotetext{
11 Referências completas: GORZ, André. Capitalism, socialism, ecology. Rio de Janeiro: Verso, 1994; POLANYI, Karl. A grande transformação: origens da nossa época. Rio de Janeiro: Campus, 2000; MARTINEZ-ALIER, Joan. Ecological economics. In: International Encyclopedia of the Social and Behavioral Sciences. 2015; LÖWY, Michael. What Is Ecosocialism? Tradução de Eric Canepa. In: Capitalism, Nature, Socialism. 2, n¹6, p. 15-24. 2005.

${ }^{12}$ Referências completas: FREIRE, Paulo. Pedagogia da Autonomia: saberes necessários à prática educativa. São Paulo: Paz e Terra. 29a ed., 2004; LEFF, Enrique. Epistemologia Ambiental. São Paulo: Cortez, $4^{a}$ ed., 2006; BOFF, Leonardo. Saber cuidar. Petrópolis: Editora Vozes, 1999.

${ }^{13}$ Referências completas: BAKHTIN, Mikhail. Marxismo e filosofia da linguagem: problemas fundamentais do método sociológico na ciência da linguagem. São Paulo: Hucitec, $9^{a}$ edição. 1999; VYGOTSKY, Levi. A formação social da mente. São Paulo: Martins Fontes, 1984.
} 
nos países localizados no hemisfério Sul, utilizando a revisão sistemática da literatura sobre o tema. Entre as distintas discussões suscitadas, está a perspectiva biofísica, a economia ecológica e os impactos nelas decorrentes. Ao longo de sua pesquisa, a tradição marxista emerge em momentos específicos da sua discussão. Inicialmente, o autor recupera Arturo Escobar (2015), Ruy Marini (2005) e Maria Amelia Enríquez (2010) ${ }^{14}$ ao falar da emergência da Teoria da Dependência de orientação marxista nos anos 1960 e 1970 nas Ciências Sociais. Posteriormente, ao falar sobre a relação entre decrescimento e questões demográficas, recupera os escritos de Joan Martínez-Alier (2012) e Christian Kerschner (2010) ${ }^{15}$ para falar das influências marxistas nas posturas antimalthusianas e as raízes da economia ecológica. Mais para o final da pesquisa, Silva (2017) aponta a necessidade de pesquisas futuras referentes às jornadas de trabalho $e$ às consequências do decrescimento, recuperando James O'Connor e Michael Löwy. Pesquisas com uma metodologia baseada na revisão sistemática completa da literatura, segundo nosso entendimento, precisam reconhecer o papel da tradição do Marxismo e se aproximando de debates presentes no Marxismo Ecológico, como a referida pesquisa realiza.

Tratando-se agora da busca realizada com o termo "Ecossocialismo", no Catálogo de Teses e Dissertações do Portal da Capes, encontramos 14 pesquisas (todas dissertações), de diferentes áreas de concentração. Destas, três foram da área do Direito (sendo uma mais específica da subárea do Direito Ambiental); duas da área de Economia, duas da área de Ciências Sociais (sendo uma específica da subárea da Sociologia) e uma pesquisa em cada uma das seguintes áreas: Educação, Filosofia, Ecologia Aplicada, Geografia, Desenvolvimento e Meio Ambiente, Sustentabilidade e Serviço Social. Cabe destacar que deste total, apenas três correspondiam à grande área do

\footnotetext{
${ }^{14}$ Referências completas: ESCOBAR, Arturo. Degrowth, postdevelopment, and transitions: a preliminary conversation. In: Sustainability Science, n. 10, p. 451-462, 2015; MARINI, Ruy Mauro. Vida e obra. São Paulo: Expressão Popular, 2005; ENRÍQUEZ, Maria Amelia. Trajetórias do desenvolvimento: da ilusão do crescimento ao imperativo da sustentabilidade. Rio de Janeiro: Garamon, 2010.

${ }^{15}$ Referências completas: MARTÍNEZ-ALIER, Joan. Environmental justice and economic degrowth: an alliance between two movements. In: Capitalism Nature Socialism, v. 23, n. 1, p. 51-73, 2012; KERSCHNER, Christian. Economic de-growth vs. steady-state economy. In: Journal of Cleaner Production, v. 18, n. 6, p. 544-551, 2010.
} 
conhecimento em Ciências Ambientais. Uma destas era a pesquisa de Bakri (2018), encontrada anteriormente na busca com os termos "marxismo" e "ecológico" e já referenciada neste artigo.

A segunda pesquisa, intitulada Sustentabilidade: A perda do caráter estrutural do conceito (2009), é oriunda do Programa em Ecologia Aplicada da Escola Superior de Agricultura "Luiz de Queiroz" da Universidade de São Paulo, tendo como autora a pesquisadora Camila Sasahara. Nesta pesquisa é recuperado o sentido epistemológico do conceito "Sustentabilidade Ambiental", dentro de uma revisão teórica dos paradigmas cartesiano e econômico, revelando suas consequências na degradação socioambiental. Um dos elementos que a pesquisadora recupera é a tradição do Ecossocialismo identificada dentro da categoria "Ecologia Radical", trazendo pensadores como Enrique Leff e Michel Löwy (já referenciados nos estudos anteriores). Também chamado de Socialismo Ecológico, a pesquisadora recupera, dentre outros, Ulrich Brand e Christoph Görg (2001) e Kenneth Gould, David Pellow e Allan Schnaiberg $(2004)^{16}$. Concluindo sua discussão sobre essa definição afirma que essa corrente pode ser descrita como uma tradição radical que "representa o sentido epistemológico do conceito de sustentabilidade ambiental, interpretado pela corrente ecossocialista, compreendida na vertente radical (SASAHARA, p.136, 2009).

Por último, a terceira pesquisa refere-se à dissertação de João Paulo do Vale de Medeiros, intitulada Ecossocialismo: a gênese de uma ecologia social em assentamentos de Reforma Agrária a partir dos movimentos sociais do campo (2013), defendida no Programa de Pós-Graduação em Desenvolvimento e Meio Ambiente, da Universidade Federal do Rio Grande do Norte. A partir da associação entre a crise ecológica e o modo de produção capitalista, o autor realiza uma revisão bibliográfica sobre a produção internacional do ecossocialismo, uma estudo bibliográfico da literatura nacional

\footnotetext{
${ }^{16}$ Referências completas: BRAND, Ulrich; GÖRG, Christoph. The regulation of the market and the transformation of the societal relationships with nature. In: Capitalism Nature Socialism, London: Routledge; Francis Group, v. 12, n.4, p.67-94, Dec. 2001; GOULD, Kenneth.; PELLOW, David; SCHNAIBERG, Allan. Interrogating the treadmill of production: everything you wanted to know about th treadmill but were afraid to ask. Organization \& Environment, London, v.17, p. 296-316, 2004
} 
e uma análise de como se relacionam os princípios e práticas adotados por movimentos ligados à Via Campesina com a corrente ecossocialista (analisando de modo mais direcionado um assentamento da reforma agrária localizado no Rio Grande do Norte). Os autores referenciados no estudo assemelham-se, em grande medida, aos já trazidos nas pesquisas anteriores (Leff, Martínez-Alier, Löwy, O’Connor e Foster). Há ainda referências substanciais ao geógrafo brasileiro Carlos Walter Porto-Gonçalves (2004) e ao filósofo e sociólogo francês Henri Lefebvre $(2011)^{17}$. Trazendo as premissas da perspectiva ecossocialista para a reflexão sobre a luta pela reforma agrária no Brasil, o autor conclui que:

A luta pela reforma agrária encabeçada pelos movimentos sociais está dentro desse imbricado contexto de teorias e práticas emancipatórias. E é a partir dela que emerge um novo rural, marcadamente influenciada por ideias críticas ao sistema atual e apontando caminhos que passam pela ressignificação da terra enquanto bem essencial e da coletividade. (MEDEIROS, 2013, p.55)

Para finalizar, sintetizamos no quadro abaixo o conjunto de pesquisas aqui trazido, apresentando as referências e formas de diálogo com a perspectiva do Marxismo Ecológico.

Quadro 1: Pesquisas que dialogam com a perspectiva do Marxismo Ecológico/Ecossocialismo

\begin{tabular}{|l|l|l|}
\hline \multicolumn{1}{|c|}{ Pesquisador } & \multicolumn{1}{|c|}{ Título } & $\begin{array}{l}\text { Autores citados oriundos da } \\
\text { tradição marxista }\end{array}$ \\
\hline Alexander Salah Bakri, & $\begin{array}{l}\text { Valor e Sustentabilidade: } \\
\text { Um estudo comparativo } \\
\text { entre Economia Ambiental } \\
\text { Neoclássica, Economia } \\
\text { Ecológica e Marxismo } \\
\text { Ecológico (2018) }\end{array}$ & $\begin{array}{l}\text { Allan Schaiberg (2002); James } \\
\text { O'Connor (1988); John } \\
\text { Bellamy Foster (2016); André } \\
\text { Gorz (1994); Karl Polanyi } \\
(2000) ; \text { Joan Martínez-Alier } \\
(2015) ; \text { Michael Löwy (2005). }\end{array}$ \\
\hline $\begin{array}{l}\text { Maria da Conceição } \\
\text { Reis Maia }\end{array}$ & $\begin{array}{l}\text { Contribuições do Curso } \\
\text { Superior de Tecnologia } \\
\text { em Gestão Ambiental do } \\
\text { IFPE para a Formação do } \\
\text { Sujeito Ecológico (2015) }\end{array}$ & $\begin{array}{l}\text { Paulo Freire (2004); Enrique } \\
\text { Leff (2006); Leonardo Boff } \\
\text { (1999). }\end{array}$ \\
\hline Verônica & A Formação do Sujeito & Mikhail Bakhtin (1999) e \\
\hline
\end{tabular}

17 Referências completas: PORTO-GONÇALVES, Carlos Walter. O desafio ambiental: Os porquês da desordem mundial. Rio de Janeiro: Editora Record, 2004; LEFEBVRE, Henri. Marxismo. Porto Alegre: L\&PM, 2011. 
AMBIENTE \& EDUCAÇÃO

ISSN- 1413-8638

E-ISSN - 2238-5533

v. 23, n. 3, p. 85-104, 2018

\begin{tabular}{|c|c|c|}
\hline Rodrigues da Silva & $\begin{array}{l}\text { Ecológico no Instituto } \\
\text { Capibaribe (2016) }\end{array}$ & Vygotsky $(1984,1993)$. \\
\hline Gabriel Trettel Silva & $\begin{array}{l}\text { O decrescimento: leituras } \\
\text { a partir do Sul global } \\
(2017)\end{array}$ & $\begin{array}{lr}\text { Arturo Escobar (2015), } & \text { Ruy } \\
\text { Marini (2005) e Maria } & \text { Amelia } \\
\text { Enríquez (2010); } & \text { Joan } \\
\text { Martínez-Alier } & \text { (2012); } \\
\text { Christian Kerschner } & \text { (2010); } \\
\text { James O’Connor } & \text { (1988) } \\
\text { Michael Löwy (2005). } & \end{array}$ \\
\hline Camila Sasahara & $\begin{array}{l}\text { Sustentabilidade: } \\
\text { perda do A } \\
\text { estrutural do conáter } \\
(2009)\end{array}$ & $\begin{array}{l}\text { Enrique Leff } \text { (2001); } \text { Michel } \\
\text { Löwy (2005); Ulrich Brand; } \\
\text { Christoph Görg } \quad \text { (2001); } \\
\text { Kenneth Gould, David } \\
\text { Pellow e Allan Schnaiberg } \\
\text { (2004). }\end{array}$ \\
\hline $\begin{array}{l}\text { João Paulo do Vale de } \\
\text { Medeiros }\end{array}$ & $\begin{array}{l}\text { Ecossocialismo: a gênese } \\
\text { de uma ecologia social em } \\
\text { assentamentos } r \text { de } \\
\text { Reforma Agrária a partir } \\
\text { dos movimentos sociais } \\
\text { do campo (2013) }\end{array}$ & $\begin{array}{l}\text { Enrique Leff } \quad \begin{array}{r}\text { (2001);Joan } \\
\text { Martínez-Alier; }\end{array} \\
\text { Löwy;James O'Connor;John } \\
\text { Bellamy Foster;Carlos Walter } \\
\text { Porto-Gonçalves (2004); Henri } \\
\text { Lefebvre (2011). }\end{array}$ \\
\hline
\end{tabular}

Fonte: Elaborado pelos autores (2018).

O conjunto de pesquisas aqui recuperadas constitui, portanto, um mapa dos estudos, pesquisadores e discussões que trabalham com o Marxismo Ecológico no campo de pesquisas produzidas nas Ciências Ambientais no Brasil. Ele expressa a existência ainda tímida desta perspectiva teórica nos estudos brasileiros, abrindo, por consequência, inúmeras possibilidades a serem ainda exploradas e desenvolvidas, em intersecções fecundascom as contribuições da chamada Sociologia Ambiental.

\section{CONSIDERAÇÕES FINAIS}

Após a recuperação da constituição de um "pensamento ecológico" em Marx, a partir, especialmente, de um conjunto de autores da chamada Sociologia Ambiental, foi-nos possível apreender a riqueza das contribuições teóricas desta perspectiva e sua potencialidade para as análises atuais sobre a questão ambiental. Contudo, apesar da riqueza referida, observamos no contexto brasileiro uma tímida e ainda incipiente inserção destas contribuições, no que se refere aos estudos que, de um modo geral, procuram analisar a 
questão ambiental (pensada para além da Sociologia Ambiental). Quando focamos nosso olhar ao campo de estudos específico das Ciências Ambientais, a fraca inserção torna-se ainda mais evidente.

Além disso, constatamos por meio de um mapeamento no Catálogo de Teses e Dissertações da Capes, que as poucas pesquisas existentes nas Ciências Ambientais encontram-se fragmentadas nas seguintes direções: utilização do Marxismo Ecológico pelas suas contribuições à economia ecológica; discussão sobre o papel da educação ambiental na perspectiva crítica, mais especificamente, no que diz respeito à formação de educadores e do sujeito ecológico; utilização da perspectiva marxista para a problematização do conceito de sustentabilidade e para a análise teórico-empírica depossíveis interrelações entre os princípios e valores do chamado Ecossocialismo com experiências concretas de movimentos sociais.

Nos estudos analisados encontramos referenciados, em boa medida, os teóricos apresentados na primeira parte deste artigo, oriundos do campo de estudos do Marxismo Ecológico na Sociologia Ambiental. Acreditamos que isto expressa a fecunda interlocução, ainda a ser construída e aprofundada, entre a Sociologia Ambiental e as Ciências Ambientais, apontando para uma agenda futura de pesquisas interdisciplinares sobre a questão ambiental. Nestas, por meio do Marxismo Ecológico/Ecossocialismo, acreditamos ser possível avançar numa análise crítica acerca da chamada crise ambiental, superando posturas simplistas ou mesmo "superficiais" que, ao não tratarem de modo mais substancial dos aspectos estruturais do modo de produção capitalista (considerando as contribuições mais recentes acerca dele), acabam muitas vezes por negligenciar as relações existentes entre a degradação ambiental e o aprofundamento de desigualdades econômico-sociais, assim como a permanência de imbricadas relações de exploração Norte-Sul, nas quais a espoliação da natureza é uma constante.

\section{REFERÊNCIAS BIBLIOGRÁFICAS}

BOURDIEU, Pierre; CHAMBOREDON, Jean-Claude.; PASSERON, JeanClaude. O ofício do sociólogo. Petrópolis: Vozes, 1991. 
BUTTEL, Frederick H. A sociologia e o meio ambiente: um caminho tortuoso rumo à ecologia humana. Perspectivas: Revista de Ciências Sociais, v. 15, n. 1, 1992.

CLARK, Brett; FOSTER, John Bellamy. Imperialismo ecológico y la fractura metabólica global. Intercambio desigual y el comercio de guano/nitratos. In: Theomai, n. 26, 2012.

ESCALERA-BRICEÑO, Alejandro; ÁNGELES-VILLA, Manuel; PALAFOXMUÑOZ, Alejandro. ¿Por qué se debe considerar al marxismo ecológico en la era del capitaloceno? In: Letras Verdes. Revista Latinoamericana de Estudios Socioambientales, n. 23, p. 69-90, 2018.

FOSTER, John Bellamy. A ecologia da economia política marxista. In: Lutas Sociais, n. 28, p. 87-104, 2012.

FLEURY, Lorena Cândido; ALMEIDA, Jalcione Pereira de; PREMEBIDA, Adriano. $O$ ambiente como questão sociológica: conflitos ambientais em perspectiva. In: Sociologias. Porto Alegre. Vol. 16, n. 35 (jan./abr. 2014), p. 3482, 2014.

MAIA, Maria da Conceição Reis. Contribuições do Curso Superior de Tecnologia em Gestão Ambiental do IFPE para a Formação do Sujeito Ecológico. Dissertação (Mestrado em Gestão Ambiental) - Instituto Federal de Educação, Ciência e Tecnologia de Pernambuco. Recife, 2015. 98f.

MARX, Karl. O Capital, vol. I. São Paulo: Abril Cultural, 1983.

MEDEIROS, João Paulo do Vale de. Ecossocialismo: a gênese de uma ecologia social em assentamentos de reforma agrária a partir dos movimentos sociais do campo. Dissertação (Mestrado em Meio Ambiente, Cultura e Desenvolvimento) - Universidade Federal do Rio Grande do Norte, Natal, 2013. $80 f$.

O'CONNOR, James. Causas naturales: Ensayos de marxismo ecológico. México: Siglo XXI editores, 2001.

OLIVIERI, Alejandro Gabriel. A teoria da modernização ecológica: uma avaliação crítica dos fundamentos teóricos. Tese (Doutorado em Sociologia)Universidade de Brasília. Brasília, 2009. 199f.

POLANYI, Karl. A grande transformação: origens da nossa época. Rio de Janeiro: Campus, 2000.

SASAHARA, Camila. Sustentabilidade: A perda do caráter estrutural do conceito.Dissertação (Mestrado em Ecologia Aplicada - Escola Superior de Agricultura "Luiz de Queiroz" da Universidade de São Paulo. Piracicaba, 2009. $200 f$.

SCHNAIBERG, Allan. Social Syntheses of the Societal-Environmental Dialectic: The Role of Distributional Impacts. In: Social Science Quarterly, v. 56, p. 5-20, 1975. 
SCHNAIBERG, Allan; WEINBERG, Adam; PELLOW, David. Politizando la rueda de producción: Los programas de reciclaje de residuos solidos en Estados Unidos. In: Revista Internacional de Sociología, $n^{\circ} 19-20$, p. 181222, 1998.

SILVA, Gabriel Trettel. O decrescimento: leituras a partir do Sul global. Dissertação (Mestrado em Ciência Ambiental) - Instituto de Energia e Ambiente da Universidade de São Paulo. São Paulo, 2017. 114 f.

SILVA, Veronica Maria Rodrigues da. A formação do sujeito ecológico no Instituto Capibaribe. Dissertação (Mestrado profissional em Gestão Ambiental) - Instituto Federal de Educação, Ciência e Tecnologia de Pernambuco. Recife, $2016155 f$. 